\title{
Increased Numbers of Heat-resistant Spores Produced by Two Strains of Clostridium perfringens Bearing Temperate Phage s9
}

\author{
By ADELLE W. STEWART* AND MICHAEL G. JOHNSON \\ Departments of Food Science and Microbiology, Clemson University, \\ Clemson, South Carolina 2963I, U.S.A.
}

(Received 23 June 1977)

\begin{abstract}
Sporulation kinetics and spore heat resistance data were compared for a lysogenic strain of Clostridium perfringens, s9, before and after curing with ultraviolet irradiation. The cured strain showed the same growth rate in broth media as the lysogenic strain but took $6 \mathrm{~h}$ longer to form refractile spores. For lysogenized and cured strains the percentages of refractile spores produced that were heat-resistant $\left(80^{\circ} \mathrm{C}\right.$ for $\left.15 \mathrm{~min}\right)$ were 50 and 0.2 , respectively. When reinfected with the temperate phage, the cured strain produced spores in 2 to $3 \mathrm{~h}$, like the original lysogenic culture, and $10 \%$ of the spores produced were heat-resistant.
\end{abstract}

\section{INTRODUCTION}

Lysogeny in Clostridium perfringens was first demonstrated by Smith (1959) who characterized several temperate phages. Mahony \& Kalz (1968) isolated and characterized a temperate phage from cells of a lysogenic strain of $C$. perfringens, $\mathrm{s} 9$, which they induced with ultraviolet light. This phage showed incomplete lysis of broth cultures with latent and release periods of $45 \mathrm{~min}$ each in indicator strain SI3. Maximum titres of this phage were $\mathrm{I} \times 1 \mathrm{IO}^{4}$ to $\mathrm{I} \times \mathrm{IO}^{5}$ plaque-forming units (p.f.u.) $\mathrm{ml}^{-1}$. A second isolated phage (Mahony \& Easterbrook, I970) caused complete lysis of broth cultures of host cells and produced somewhat higher phage titres of about $\mathrm{I} \times \mathrm{IO}^{6}$ p.f.u. $\mathrm{ml}^{-1}$.

No studies of effects of bacteriophages on spore production by $C$. perfringens have, to our knowledge, been reported. Duncan, Strong \& Sebald (1972) reported that the temperate phages they tested apparently did not affect enterotoxin production. Any such information would be very useful because these workers have presented convincing evidence that $C$. perfringens produces a protein enterotoxin during sporulation. Certain strains during sporulation apparently overproduce a spore coat protein that is antigenically like the enterotoxin. Sporulation-negative mutants produced little or no enterotoxin (Duncan, I973; Duncan, King \& Frieben, 1973). Their evidence therefore suggests that any treatment which reduces sporulation of $C$. perfringens will also reduce enterotoxin production and hence decrease the organism's ability to cause foodborne illness.

In vitro studies with strains of $C$. perfringens generally show relatively low spore to bacterium ratios of 0.01 to 0.10 . If the model of Duncan et al. (1972) is correct, however, this organism must sporulate well in vivo since it is one of three major causes of bacterial foodborne gastroenteritis in the United States.

With this apparent paradox in mind, we examined the sporulation characteristics of two $C$. perfringens strains lysogenized or cured of bacteriophage. The hypothesis tested

* Present address: Department of Natural Sciences, South Carolina State College, Orangeburg, South Carolina 291 I 5, U.S.A. 
was whether the presence or absence of phage in host cells exerted any effects on sporulation. A preliminary report of this work was presented earlier (Stewart \& Johnson, 1975).

\section{METHODS}

Bacterial and bacteriophage strains. The strains of $C$. perfringens used were s9, a lysogenic strain, and si3, an indicator strain, both obtained from Dr D. E. Mahony, Dalhousie University, Halifax, Nova Scotia, Canada. Strain s9 when cured of its prophage, s9, with ultraviolet (u.v.) light (Mahony \& Kalz, 1968) was designated as s9C. Phage s9 produced a lytic effect on s9C. When surviving cells of s9C in or near plaques were transferred to tryptone/yeast extract/glucose broth (TYG broth; Bioquest, BBL) and incubated for 5 days at $30^{\circ} \mathrm{C}$, phages were detectable by u.v. induction. One such strain after isolation and purification was designated S9CR and used in further studies. Strain SI 3 when lysogenized with prophage s9 was designated SI3I.

Media. All strains of $C$. perfringens were maintained in Brewer's cooked meat medium (Difco). Thioglycollate broth (Bioquest, BBL) was used for vegetative growth, and the medium of Duncan \& Strong (1968) (DS medium) was used for spore production. Host strains for phage production were grown in Brain Heart Infusion broth (Difco) containing $0.1 \%(\mathrm{~W} / \mathrm{v})$ sodium thioglycollate (BHI broth).

Growth conditions. All cultures, unless stated otherwise, were grown at $37^{\circ} \mathrm{C}$. Oxygen was exhausted from liquid media by heating culture tubes in a boiling water bath for $5 \mathrm{~min}$ and then cooling them before inoculation. Bacteria and spores were counted on solid media by the Gas Pak method (Bioquest, ${ }^{\prime} \mathrm{BBL}$ ) or the pouch method of Bladel \& Greenberg (1965). Pouches were made by sealing together two layers of plastic laminate film (R460, W. R. Grace Co., Cryovac Division, Duncan, South Carolina, U.S.A.) having low oxygen permeability. Total bacteria and refractile spore counts were determined microscopically with a Petroff-Hauser counting chamber and a phase contrast microscope (Zeiss Standard Model RA) by the method of Meynell \& Meynell (1970). Growth of strains of $C$. perfringens was measured using matched $13 \times 100 \mathrm{~mm}$ screw-capped test tubes, containing $6 \mathrm{ml}$ thioglycollate medium inoculated with $0.1 \mathrm{ml}$ of a culture grown in this medium at $37^{\circ} \mathrm{C}$ for $4 \mathrm{~h}$. These cultures were incubated at $37{ }^{\circ} \mathrm{C}$ and growth was monitored hourly, for $\mathrm{I} 2 \mathrm{~h}$, by following changes in absorbance with a Turner Model 330 spectrophotometer at $600 \mathrm{~nm}$.

Induction of prophage s9. Clostridium perfringens s9 grown in BHI broth for $6 \mathrm{~h}$ was centrifuged at $22{ }^{\circ} \mathrm{C}$ for Io $\mathrm{min}$ in an I.E.C. HN-S centrifuge at $4500 \mathrm{rev} . \mathrm{min}^{-1}$. The resulting pellet was washed twice by centrifugation and resuspended in $0.85 \%(\mathrm{w} / \mathrm{v}) \mathrm{NaCl}$. Washed suspension $(5 \mathrm{ml})$ was placed in an open, sterile Petri dish and exposed to two 15 W General Electric (GI5 T8) germicidal lamps at a distance of $38 \mathrm{~cm}$ for $100 \mathrm{~s}$. After irradiation, I ml samples were placed in $9 \mathrm{ml}$ BHI broth and incubated for I $50 \mathrm{~min}$, then centrifuged to pellet the organisms. Supernatant fluid was assayed for p.f.u. on lawns of indicator strain SI3 by the double layer method of Adams (1959). The base layer used was the medium of Mahony \& Kalz (1968) and the overlay was $0.6 \%$ (w/v) Noble agar (Difco).

Curing of lysogenic strain 59 . Clostridium perfringens strain $\mathrm{s} 9\left(0.1 \mathrm{ml}\right.$, containing $10^{5}$ exponential-phase organisms) was spread on the surface of a plate of the agar medium of Mahony \& Kalz (1968). The inoculated plate was irradiated with the two u.v. lamps described above for $60 \mathrm{~s}$ at a distance of $20 \mathrm{~cm}$, and then incubated in a Gas Pak jar for $24 \mathrm{~h}$. Survivors formed two types of colonies; they either had a turbid clearing zone in the centre or they did not have such a zone. Colonies of the former type were transferred to BHI broth and incubated at $37^{\circ} \mathrm{C}$. When cultures reached their exponential phase of growth they were again irradiated with u.v. light to induce any prophage still remaining. Induced organisms showing no detectable phages when spotted on lawns of SI 3 were considered to be cured of the prophage s9 and designated s9C. This was confirmed by the method of Siddiqui et al. (1974), using mitomycin C (I $\mu \mathrm{g} \mathrm{ml}^{-1}$ ).

Lysogenization of the cured strain s9C and indicator strain SI3. Strains s9C and si 3 were each plated with phage s9. The plated cultures were incubated in a Gas Pak jar for $24 \mathrm{~h}$ and observed for plaques. Cells near the edges of and within plaques were picked with a platinum inoculating needle, transferred to TYG broth and incubated at $30^{\circ} \mathrm{C}$ for 5 days. Cultures which developed from such plaque areas were shown to harbour the prophage $s 9$ using the u.v. induction procedure described above and lawns of the indicator strain si3. The relysogenized strain of s9C was designated as S9CR, and the lysogenized strain of SI3 as SI3I.

Sporulation. A vegetative culture was obtained by inoculating $0.1 \mathrm{ml}$ of a culture from cooked meat medium into $10 \mathrm{ml}$ thioglycollate medium and incubating at $37^{\circ} \mathrm{C}$ for $\mathrm{I} 6 \mathrm{~h}$. Two subsequent $\mathrm{I} \mathrm{ml} \mathrm{serial}$ transfers were made into thioglycollate medium ( $10 \mathrm{ml}$ ) and each was incubated for $4 \mathrm{~h}$. The third culture was then centrifuged at $22^{\circ} \mathrm{C}$ in an I.E.C. HN-S centrifuge at $4500 \mathrm{rev}$. $\mathrm{min}^{-1}$ for Io min. The cell pellet was suspended in DS medium (ro ml) which had previously been heated in a boiling water bath for 5 min and cooled to $37^{\circ} \mathrm{C}$. Cultures were incubated at $37^{\circ} \mathrm{C}$ for $24 \mathrm{~h}$. To determine the number of heat-resistant 
Table I. Comparison of numbers of refractile and heat-resistant spores produced by lysogenic and cured strains of $C$. perfringens in DS medium

$\begin{array}{lcccc}\text { Max. no. of } & \begin{array}{c}\text { Time } \\ \text { refractile } \\ \text { spores }\left(\mathrm{ml}^{-1}\right)\end{array} & \begin{array}{c}\text { Percentage of } \\ \text { of refractile } \\ \text { spores }(\mathrm{h})\end{array} & \begin{array}{c}\text { Time } \\ \text { refractile spores } \\ \text { that were } \\ \text { heat-resistant }\end{array} & \begin{array}{c}\text { for max. no. of } \\ \text { heat-resistant } \\ \text { spores }(\mathrm{h})\end{array} \\ \text { S9 } & \mathrm{I} \times 10^{7} & 3 & 50 \cdot 0 & 3 \\ \text { S9C } & \mathrm{I} \times 10^{6} & 9 & 0 \cdot 2 & 9-10 \\ \text { S9CR } & 2 \times 10^{7} & 4 & 10 \cdot 0 & 4 \\ \text { SI3 } & \mathrm{ND} & 3 & 2 \cdot 0 & 8 \\ \text { SI3I } & \mathrm{I} \times 10^{7} & & & 5-6 \\ \text { ND, Not detectable. } & & & \end{array}$

spores, suspensions in tubes were heated in an oil bath at $80{ }^{\circ} \mathrm{C}$ for $\mathrm{I} 5 \mathrm{~min}$, diluted with $0 . \mathrm{I} \%$ (w/v) peptone, plated on Brewer's anaerobic agar (Difco) and incubated in Gas Pak jars for $48 \mathrm{~h}$ at $37{ }^{\circ} \mathrm{C}$.

After sporulation, cultures were harvested as above. Their dipicolinic acid (DPA) content was determined by the method of Janssen, Lund \& Anderson (1958) using pellets from non-sporulated cultures as controls. DPA used to prepare standard curves was purchased from Sigma. Pellet dry weights were determined after drying samples of cultures in aluminium dishes to constant weight at $100^{\circ} \mathrm{C}$.

Data presented are the average values of duplicate experiments.

\section{RESULTS}

\section{Strain and phage characteristics}

The growth rate constants ( $k$, expressed as the number of doublings per hour) for the lysogenic strain s9, the cured strain S9C and the relysogenized strain S9CR in thioglycollate broth were similar, being $\mathrm{I} \cdot 2$ to $\mathrm{I} \cdot 3 \mathrm{~h}^{-1}$. The values of $k$ for the indicator strain SI 3 and the lysogenized strain SI $3 \mathrm{I}$ were $\mathrm{I} \cdot 0$ to $\mathrm{I} \cdot \mathrm{I} \mathrm{h}^{-1}$. Strains S9CR and SI3I, unlike their respective parent strains, had lag periods of 2 to $3 \mathrm{~h}$ before exponential growth started. All the s9 strains had similar mucoid colonies.

On lawns of si3, phage s9 produced turbid plaques that had irregular edges and an average diameter of $\mathrm{I} \mathrm{mm}$. These small plaques were difficult to see unless viewed against a dark background with oblique lighting.

Complete lysis of $C$. perfringens $\mathrm{S}{ }_{3} 3$ by s9 was never observed in liquid media although there was always some increase in phage titre. Serial transfers of phage lysate to fresh cultures of SI 3 increased the phage concentration to no more than $\mathrm{I} \times 10^{5}$ p.f.u. $\mathrm{ml}^{-1}$. Apparently, the bacteria remaining in the culture either became resistant to phage adsorption and infection or became lysogenized.

\section{Spore production}

The total microscopically-refractile and heat-resistant spore counts produced by the lysogenized strain s9, the cured strain S9C and the reinfected strain S9CR in DS medium were compared. Strain $\$ 9$ produced maximum numbers of refractile spores $\left(\mathrm{I} \times \mathrm{IO}^{7} \mathrm{ml}^{-1}\right)$ by about $3 \mathrm{~h}$ compared with $9 \mathrm{~h}$ for s9C and $4 \mathrm{~h}$ for s9CR (Table I). While strains s9, s9C and S9CR required corresponding periods $(3,9$ to 10 , and $4 \mathrm{~h})$ to form maximum numbers of heat-resistant spores, the percentages of refractile spores that were heat-resistant differed, being $50,0.2$ and 10 , respectively.

Cultures of the indicator strain SI3 initiated sporulation in 3 to $4 \mathrm{~h}$ and produced maximum numbers of heat-resistant spores (about $5 \times 10^{5} \mathrm{ml}^{-1}$ ) by $8 \mathrm{~h}$ (Table I). Since refractile spores were apparently produced in numbers too low to be enumerated microscopically, even after $\mathrm{I} 2 \mathrm{~h}$, the percentage of spores produced that were heat-resistant could not be calculated. 
Table 2. Dipicolinic acid content of sporulated suspensions produced by lysogenic and cured strains of $C$. perfringens

$\begin{array}{lr}\text { Strain } & \begin{array}{r}\text { DPA con } \\ \text { [ } \mu \text { mol (g dry wt }\end{array} \\ \text { S9 } & 2 \cdot 7 \\ \text { S9C } & \text { I.2 } \\ \text { S9CR } & 2 \cdot 2 \\ \text { SI3 } & 4 \cdot 7 \\ \text { SI 3I } & 2 \cdot 6\end{array}$

Strain SI3I, i.e. strain SI3 lysogenized with phage s9, initiated sporulation in I to $2 \mathrm{~h}$ but required 5 to $6 \mathrm{~h}$ to produce maximum numbers of heat-resistant spores $\left(5 \times 10^{5} \mathrm{ml}^{-1}\right)$ (Table I). Maximum numbers of refractile spores $\left(\mathrm{I} \times 1 \mathrm{I}^{7} \mathrm{ml}^{-1}\right)$ were observed microscopically after $3 \mathrm{~h}$ and $2 \%$ of these were heat-resistant.

\section{Dipicolinic acid content of spores}

Expressed as $\mu$ moles per g dry weight bacteria, the amounts of DPA in the endospores produced by the five strains varied little, ranging from $\mathrm{I} \cdot 2$ for strain S9C to $4 \cdot 7$ for strain SI3 (Table 2).

\section{DISCUSSION}

Clostridium perfringens, unlike many other clostridia and most bacilli, sporulates relatively poorly in laboratory media. We were interested to see whether the presence of prophages in cells affected sporulation in this organism.

Strain s9CR, the cured strain into which the prophage s9 was reintroduced, produced maximum numbers of spores in about 5 to $6 \mathrm{~h}$ less time than did s9c (Table $\mathrm{I}$ ) and the percentage of heat-resistant spores was increased from 0.2 to I0 \%. Similarly, strain SI3I, the indicator strain into which the prophage s9 was introduced, produced maximum levels of heat-resistant spores in 2 to $3 \mathrm{~h}$ less time than did si3. These data argue that when temperate phage s9 was present in host strains of $C$. perfringens, it could somehow alter the way the genetic information for sporulation was read. One possibility is that this phage genome itself contained some genetic information that affected host cell sporulation, a mechanism known as 'phage conversion' (Hayes, 1968). A classic example of this mechanism is the toxigenicity which lysogenization with phages of the $\beta$ group confers on Corynebacterium diphtheriae (Freeman, I95I ; Freeman \& Morse, 1952). A second possibility is that phage s9, when induced out of host cells, transferred host sporulationspecific genes to recipient cells, a mechanism known as phage transduction (Zinder \& Lederberg, I952). Before one can unequivocally judge which of these mechanisms is operating in this prophage-host system, genetic markers in $C$. perfringens coding for non-sporulation specific functions but close to those for sporulation will have to be mapped. In the interim, the high frequency with which sporulation was altered as the prophage was removed from or reinstated in cells argues in favour of the phage conversion hypothesis. This hypothesis is strengthened by the data of Grant \& Riemann (1976) who found that three temperate phages isolated from lysogenic strains of $C$. perfringens Type $C$ were apparently unable to transduce erythromycin resistance.

Until recently, dipicolinic acid was thought necessary for heat resistance in spores of clostridia and bacilli (Murrell, 1969). However, data challenging this concept have been reported. Spores of two mutant strains of Bacillus cereus and Bacillus subtilis which lacked any detectable DPA were nevertheless found to be quite heat-resistant (Hanson et al., 1972; Zytkovicz \& Halvorson, 1972). Additional work disputing the role of DPA in spore heat resistance was reported recently by Imae \& Strominger $(1976 a, b)$. They found that the development of spore heat resistance in mutant strains of Bacillus sphaericus and 
B. subtilis was more closely associated with the accumulation in the cortex region of 'muramic lactam', not DPA. We were unable to detect differences in the DPA content of sporulated suspensions of $C$. perfringens which could explain the differences in their heat resistance.

Unlike the positive effect exerted on sporulation by phage s9 which we report here, several recent studies indicate that prophages can affect sporulation negatively. Hendry, Gillespie \& Fitz-James (I976) found that sporulation proceeded faster in mutants of Bacillus medusa from which the phage $\phi$ med-2 was removed by u.v. light or mitomycin $\mathrm{C}$ treatment. Similar phage or plasmid-associated repression of sporulation in Bacillus pumilus has been reported (Lovett, 1973; Bramucci \& Lovett, I974; Lovett \& Bramucci, 1974).

This report is, to our knowledge, the first showing that sporulation and spore heat resistance in $C$. perfringens can be affected by phage. It seems obvious that caution should be exercised in attempting to interpret the results of sporulation experiments with $C$. perfringens Type A strains in which the possibility of lysogeny has not first been checked. While Sebald \& Costilow (I975) were unable to detect any transduction, transformation or conjugation mechanisms in several strains of this organism, the minimal medium they developed to detect auxotrophic mutants along with the phage system we report here should prove useful in deciphering the genetic mechanisms controlling sporulation in this organism.

Technical Contribution No. I39I of the South Carolina Agricultural Experiment Station, Clemson, South Carolina 2963r, U.S.A.

This research was supported in part by a fellowship awarded to A.W.S. from the Ford Foundation and the National Fellowships Fund and in part by funds provided to the South Carolina Agricultural Experiment Station for Hatch Project SCo00006 from the United States Department of Agriculture. The authors thank Ann W. Baxter, M. J. B. Paynter and S. S. Hayasaka for helpful discussions. This paper was taken in part from a thesis submitted by A.W.S. to Clemson University in partial fulfilment of the requirements of the Ph.D. degree.

\section{REFERENCES}

Adams, M. H. (1959). Bacteriophages. New York: Interscience.

Bladel, B. O. \& Greenberg, R. A. (I965). Pouch method for the isolation and enumeration of clostridia. Applied Microbiology r3, 28I-285.

Bramucci, M. G. \& LovetT, P. S. (1974). Temperate bacteriophage infectious for asporogenic variants of Bacillus pumilus. Journal of Virology 14, I28II287.

DuncaN, C. L. (1973). Time of enterotoxin formation and release during sporulation of Clostridium perfringens Type A. Journal of Bacteriology $\mathbf{1}_{3}$, 932-936.

Duncan, C. L. \& Strong, D. H. (I968). Improved medium for sporulation of Clostridium perfringens. Applied Microbiology 16, 82-89.

Duncan, C. L., Strong, D. H. \& Sebald, M. (1972). Sporulation and enterotoxin production by mutants of Clostridium perfringens. Journal of Bacteriology I Io, 378-39I.

Duncan, C. L., King, G. J. \& Frieben, W. R. (1973). A paracrystalline inclusion formed during sporulation. Journal of Bacteriology $\mathbf{r} 4,845^{-}$ 859.

FreEman, V. J. (I95I). Studies on the virulence of bacteriophage-infected strains of Corynebacterium diphtheriae. Journal of Bacteriology 6r, 675-688.
Freeman, V. J. \& Morse, I. U. (1952). Further observations on the change to virulence of bacteriophage-infected strains of Corynebacterium diphtheriae. Journal of Bacteriology 63, 4074I4.

GraNt, R. B. \& RiemaNN, H. P. (I976). Temperate phages of Clostridium perfringens Type C. Canadian Journal of Microbiology 22, 603-610.

Hanson, R. S., Curry, M. V., Garner, J. V. \& HALvorson, H.O. (1972). Mutants of Bacillus cereus strain $\mathrm{T}$ that produce thermoresistant spores lacking dipicolinate and have low levels of calcium. Canadian Journal of Microbiology I8, I I39-I I 43 .

HAYES, W. (1968). The Genetics of Bacteria and Their Viruses-Studies in Basic Genetics and Molecular Biology, 2nd edn. New York: John Wiley.

Hendry, G. S., Gillespie, J. B. \& Fitz-James, P. C. (I976). Bacteriophage and bacteriophage-like structures carried by Bacillus medusa and their effect on sporulation. Journal of Virology 18, IO51-1062.

ImAe, Y. \& Strominger, J. L. (I976a). Relationship between cortex content and properties of Bacillus sphaericus spores. Journal of Bacteriology 126, 907-913. 
ImAe, Y. \& Strominger, J. L. (1976b). Cortex content of asporogenous mutants of Bacillus subtilis. Journal of Bacteriology 126, 914-918.

JANSSEN, F. W., LuND, A. J. \& ANDERSON, L. E. (I958). Colorimetric assay for dipicolinic acid in bacterial spores. Science 127, 26-27.

LovetT, P. S. (1973). Plasmid in Bacillus pumilus and the enhanced sporulation of plasmid-negative variants. Journal of Bacteriology II5, 29I-298.

LovetT, P. S. \& BramucCI, M. G. (I974). Biochemical studies of two Bacillus pumilus plasmids. Journal of Bacteriology 120, 488-494.

MAHONY, D. E. \& EASTERBROOK, K. B. (1970). Intracellular development of a bacteriophage of Clostridium perfringens. Canadian Journal of Microbiology $16,983-988$.

Mahony, D. E. \& Kalz, G. C. (I968). A temperate bacteriophage of Clostridium perfringens. Canadian Journal of Microbiology 14, 1085-1093.

Meynell, G. C. \& Meynell, E. (1970). Theory and Practice in Experimental Bacteriology, 2nd edn. Cambridge: Cambridge University Press.

Murrell, W. G. (1969). Chemical composition of spores and spore structures. In The Bacterial Spore, pp. 21 5-274. Edited by G. W. Gould and A. Hurst. New York: Academic Press.
Sebald, M. \& Costilow, R. N. (1975). Minimal growth requirements for Clostridium perfringens and isolation of auxotrophic mutants. Applied Microbiology 29, I-I6.

SiddiQui, A., Hurt, E., Mandagere, U. \& GoldBERG, I. E. (1974). Rapid plate method for the isolation of lysogenic bacteriophages. Applied Microbiology 27, 278-280.

Smith, H. W. (1959). The bacteriophages of Clostridium perfringens. Journal of General Microbiology 21, 622-630.

Stewart, A. W. \& Johnson, M. G. (1975). Effect of a temperate bacteriophage of Clostridium perfringens s9 on sporulation and spore heat resistance. Abstracts of the Annual Meeting of the American Society for Microbiology, P8, 201. Washington: American Society for Microbiology. ZINDER, N. D. \& LeDERBERG, J. (I952). Genetic exchange in Salmonella. Journal of Bacteriology 64, 679-699.

Zytkovicz, T. H. \& Halvorson, H. O. (1972). Some characteristics of dipicolinic acid-less mutant spores of Bacillus cereus, Bacillus megaterium and Bacillus subtilis. In Spores V, pp. 49-52. Edited by H. H. Halvorson, R. Hanson and L. L. Campbell. Washington: American Society for Microbiology. 